\title{
SEXUAL RISK BEHAVIOUR: THE ROLES OF IMPULSIVITY, FAMILY TYPE AND PEER PRESSURE AMONG UNDERGRADUATE STUDENTS IN NIGERIA
}

\author{
OPEYEMI OYEWUNMI EKUNDAYO, OYEYEMI BUKOLA BABALOLA \\ Department of Psychology, Obafemi Awolowo University, Ile-Ife, Osun State, Nigeria
}

C 2020 Opeyemi Oyewunmi Ekundayo, Oyeyemi Bukola Babalola

This is an open access article distributed under the Creative Commons Attribution-NonCommercial-NoDerivs license (http://creativecommons.org/licenses/by-nc-nd/3.0/)

DOI: 10.1515/eras-2020-0002

\begin{abstract}
The study examined the influence of impulsivity on undergraduates' sexual risk behaviour and also scrutinized the mediating roles of family type and peer pressure on undergraduates' sexual risk behaviour in Southwestern Nigeria. The study was a descriptive survey that employed a multi-stage sampling procedure in which respondents were selected at different levels and stages. A total of 1080 respondents selected from six Universities participated in the study. Their age ranges from 15-19 years with a mean of 15.9 \pm 1.2 years. Data gathered through Impulsive Behaviour Scale and the Sexual Behaviour Inventory was analysed by t-test and ANCOVA. The result showed that impulsivity $(\mathrm{t}=6.04$, $\mathrm{df}=1078, \mathrm{p}<0.05)$ had significant influence on the sexual risk behaviour of undergraduates in Southwestern Nigeria. The result further showed that age: F $(2,1077)=18.20, \mathrm{p}<0.05$; family type $\mathrm{F}(2,1077)=25.41, \mathrm{p}<0.05$ and peer pressure $\mathrm{F}(2,1077)=53.13, \mathrm{p}<0.05$ have an intervening impact on the influence of impulsivity $\mathrm{F}(2,1073)=1.37, \mathrm{p}<0.05)$ on sexual risk behaviour of the undergraduates. The study concluded that impulsivity enhances sexual risk behaviour of undergraduates in Southwestern Nigeria.
\end{abstract}

\section{Keywords}

sexual risk behaviour, impulsivity, peer pressure, family type, undergraduates

\section{Introduction}

Adolescence is a crucial stage of human development with regards to sexuality. It is a period characterized with physical, cognitive, and emotional turmoil (Bhattacharya, 2016; Agiobu-Kemmer, 2009; Markova \& Nikitskaya, 2017; Steinberg \& Morris 2001). The rapid development and emotional changes during this stage play a critical role in an adolescent's life. Emotionally, adolescence is a turning point in the development of sexuality as it marks the onset of deliberate sexually motivated behaviour that is recognized, both by oneself and by people around, as primarily and totally sexual in nature (Ekundayo, 2014). Adolescent sexual behaviour not only critically affect adolescence but also future developmental periods. Sex can be said to be a behaviour exhibited by most humans (Wellings, 2006) and this behaviour can differ from one individual to another in terms of risk and risk related outcomes. Though, it was expressed that the sexuality of adolescent brings excitement (Freedman, 2000) yet if not well managed it could lead to anomaly of socially bearable sexual practice. Adolescents, like adults, susceptibly involve themselves in sexually risky behaviour due to feelings of personal imperviousity. Adolescents also have the predisposition to prioritize the immediate, rather than prolonged aftermath of their behaviour (Hall, Holmqvist \& Sherry, 2004; Cyders \& Smith, 2008). 
Globally, sexual risk behaviours are occurring with sufficient frequency leading to high rates of unwanted pregnancy, and sexually transmitted diseases including Human Immunodeficiency Virus and AIDS which remains a significant public health concern (World Health Organization, 2002). The World Health Organization outlined in 2002 that "unsafe sex was second among the top ten risk factors in the burden of all diseases caused globally". Researches both in the developed and developing countries have concluded that sexual risk behaviour is common with adolescents and youth. Such behaviour include early sexual debut (Durowade, Babatunde, Omokanye, Elegbede, Ayodele, et al, 2017; Nnebue, Chimah, Duru, Illika \& Lawoyin, 2016; Fatusi \& Blum, 2008), sex with multiple partners (WHO, 2000; Folayan, Odetoyinbo, Brown \& Harrison, 2014), low or inconsistent condom use, sex under influence of drugs or alcohol, oral/anal sex, and transactional sex (John, Okolo, \& Isichei, 2014; Imaledo, Peter-Kio \& Asuquo, 2012; Aboki, Folayan, Daniel \& Ogunlayi, 2014).

In Nigeria, the commencement of sexual activity before marriage is not unconventional as "nearly one-quarter of women age 25-49 have had sexual intercourse by age 15 (Envuladu, de Kwaak, Zwanikken \& Zoakah, 2017) and more than half (60\%) by age 18 with median age at sexual debut as 17.6 years for women and 21.1 years for men age 25-49" (NPopC and ICF International, 2014; Dir, Coskunpinar, \& Cyders, 2014). Furthermore, data from the National HIV and AIDS Reproductive Health Survey (NARHS, 2004) show that among sexually active adolescents aged $15-19$ years, only $34.4 \%$ used condom at their most current sexual intercourse. The NARHS in 2012 concluded that $37.4 \%$ of females and $19.7 \%$ of males aged 15 years -19 years had had sex. Use of contraception among those who had engaged in sexual intercourse was $33.6 \%$ among unmarried women and $41.0 \%$ among unmarried men. Among adolescents aged 15 to 19 years, the use of contraception was much lower - " $3.5 \%$ for women and $8.3 \%$ for men, and these rates are much lower than among youths 20 - 24 years of age" (NARHS, 2012).

Previous studies had examined varying factors that could contribute to sexual risk behaviour. Ritchwood, Ford, DeCoster, Sutton \& Lochman (2015) examined the relationship between substance abuse and sexual risky behaviour as moderated by sex, ethnicity, sexuality, age, sample type, and level of measurement. Folayan, Adebajo, Adeyemi \& Ogungbemi (2015) assessed differences in sexual practices, HIV sexual risk behaviours, and HIV risk profile. Charnigo, Noar, Garnett, Crosby, Palmgreen, \& Zimmerman (2013) studied the joint contribution of sensation seeking and impulsive decision-making to HIV and sexually transmitted disease (STD) while Ekundayo (2014) and Nnebue, Chimah, Lawoyin, Illika \& Duru (2015) examined socio-demographic characteristics determining sexual risk behaviour among adolescents. Adolescents who seem to have "deficient impulse control and emotional regulation are associated with risk-taking of all kinds, including alcohol or drug use, sexual risk behaviour" (Silverman, 2013; Winters, Botzet, Fahnhorst, Baumel, \& Lee 2008; Charnigo, 2013). There is therefore a need to understand impulsivity as behaviour without requisite thought and the propensity to act with inadequate planning than do most individuals of same intellectual ability (Madden \& Johnson, 2010). This study is therefore interested in investigating the influence of impulsivity on sexual risk behaviour with keen interest in how age, family background and peer pressure could intervene with its influence on undergraduates' sexual risk behaviour.

\section{Methods}

This study was a descriptive survey which employed a multi-stage sampling procedure. There are six states in the southwestern region of Nigeria. Three states namely Osun, Lagos and Ekiti were randomly selected. From each of the randomly selected States, two universities were purposively selected (one privately owned and one public university). Obafemi Awolowo 
University was selected as the public university in Osun State while Bowen University was selected as the privately-owned university. In Lagos State, University of Lagos (public university) and Caleb University (privately-owned) were selected. From Ekiti State, Federal University, Oye-Ekiti (public) and Afe Babalola University (privately-owned) were selected. Three Faculties were purposively selected from each University, namely Faculty of Social Sciences, Faculty of Technology, and Faculty of Health Sciences (in some of these universities, Social Sciences is referred to as Social and Management Sciences, Health Sciences as Clinical/Medical Sciences, and Technology as Engineering). Two hundred and forty (240) undergraduates were randomly selected from each public university, while one hundred and twenty (120) were randomly selected from each private university based on the variation in their students' population. Hence, a total of 1080 respondents were selected from the six selected universities.

The data collection tools used in the study was administered in the students' classrooms by the researcher. The implementation was carried out in each lecture room by the researchers, who read the Informed Volunteer Consent Form. In this respect, information about the study purpose, implementation method, confidentiality, and voluntary participation was given in the lecture room setting. Data were collected from adolescents who chose to participate in the study after these explanations. The data sets were examined after the administration; incomplete, imprecise, and incorrect data were eliminated from the study and the analyses were conducted on the remaining data.

\section{Research instruments}

The UPPS Impulsive Behaviour Scale was designed by Whiteside and Lynam in 2001. Whiteside and Lynam's (2001) UPPS model of impulsivity is one of the most widely-used formulations of the impulsivity construct. This model postulates four constructs associated with impulsive behaviour: Sensation Seeking, a tendency to engage in rash action; Urgency, a tendency toward rash action during periods of intense affect; (lack of) Premeditation, characterized by a poor ability to think through the consequences of one's actions; and (lack of) Perseverance, characterized by difficulty in following through with tasks from beginning to end. The scale was designed to measure pathways to impulsive behaviours. An adapted version was used for this study and it had 12 items. Each item carries a response format of Agree strongly $=1$, agree some $=2$, disagree some $=3$, and disagree strongly $=4$. These 12 items are summed and the higher the score the more one act and think impulsively. Cronbach's Alpha $(\alpha)$ coefficients in Whiteside and Lynam's (2001) original study were 0.86 for urgency, 0.91 for lack of premeditation, 0.82 for lack of perseverance, and 0.90 for sensation seeking. The corresponding coefficients for the French version of the UPPS were $0.83,0.83,0.81$, and 0.77 , respectively (Van der Linden et al., 2006) while the corresponding German version Cronbach's alpha $(\alpha)$ was 0.82 for urgency, 0.80 for lack of premeditation, 0.85 for lack of perseverance, and 0.83 for sensation seeking; the UPPS subscales thus demonstrated very good internal consistency. A test-retest was conducted on the adapted version to establish its internal consistency with 0.89 and a Cronbach's alpha of 0.78 .

The Sexual Behaviour Scale sought information on how often an undergraduate had been involved in specific types of sexual activity in the last three months to the study. The scale consisted of 14 items adapted from Oyedeji (2006). The items were phrased in form of sentences to which respondents can either agree or disagree (that answer if the sentence is 'true for me' or 'not true for me'). 'True for me' was scored as 1 while 'not true for me' was scored as 0 .

A test-retest was done to know the reliability of the Sexual Behaviour Scale using 20 respondents from both private and public Universities. A Cronbach's alpha coefficient was also 
done to obtain the internal consistency of 0.92 . Construct and content validity of the scales was done by consulting with my supervisor and experts in the Faculty.

\section{Results}

An independent sample t-test analysis was performed to ascertain the influence of impulsivity on the sexual behaviour of undergraduates. The dependent variable was sexual behaviour while the independent variable was impulsivity. Preliminary assumption testing was conducted to check for normality, linearity, univariate, multivariate outliner, homogeneity of variance covariance matrices, and multi-collinearity, with no serious violation noted. The results (as shown in table 1) showed that there was a statistically significant influence of impulsivity on sexual behaviour of Undergraduates, $t(1078)=-6.04, \mathrm{df}=1078 \mathrm{p}<0.05$. This finding shows that impulsivity has a significant influence on the sexual behaviour of undergraduates in Southwestern Nigeria. The result of the mean scores indicated that undergraduates with high impulse reported lower level of sexual behaviour $(\mathrm{M}=2.72, \mathrm{SD}=$ 2.40) than undergraduates with low impulse $(\mathrm{M}=4.16, \mathrm{SD}=2.53)$. This means that undergraduate with low impulse level exhibits a higher level of sexual behaviour than undergraduates with high impulse.

Table 1. Independent t-test analysis on Impulsivity and Sexual Behaviour

\begin{tabular}{ccccccc}
\hline & $\begin{array}{c}\text { Mea } \\
\mathrm{n}\end{array}$ & $\begin{array}{c}\text { Std. } \\
\mathrm{D} .\end{array}$ & $\mathrm{N}$ & $\mathrm{t}$ & $\mathrm{df}$ & Sig \\
\hline High & 2.72 & 2.398 & 125 & - & 107 & 0.00 \\
& & & & 6.037 & 8 & 1 \\
Low & 4.16 & 2.528 & 955 & & & \\
Total & 4.00 & 2.555 & $\begin{array}{c}108 \\
0\end{array}$ & & & \\
\hline
\end{tabular}

The result of the analysis of covariance (in Table 2) indicated that there is a significant effect of the covariate (age) on the influence of impulsivity on sexual behaviour of undergraduates in Southwestern Nigeria. A preliminary analysis evaluating the homogeneityof-regression assumption indicated that the covariate (age) intervenes significantly on the influence of impulsivity on the sexual behaviour of undergraduates in Southwestern Nigeria, F $(2,1077)=18.20, \mathrm{p}<0.05$. Age therefore, intervenes significantly the influence of impulsivity on the sexual behaviour of undergraduates. The Levene's test was not significant $(p<.05)$ which means we have not violated our assumption of homogeneity of variances. Thus, the hypothesis is accepted.

Table 2. Summary of ANCOVA of impulsivity on sexual behaviour by age

\begin{tabular}{llllll}
\hline Source & $\begin{array}{l}\text { Type III Sum } \\
\text { of } \\
\text { Squares }\end{array}$ & Df & $\begin{array}{l}\text { Mean } \\
\text { Square }\end{array}$ & F & Sig. \\
\hline Corrected & 230.222 & 2 & 115.111 & 18.20 & .00 \\
Model & 587.680 & 1 & 587.680 & 0 & 0 \\
Intercept & 230.222 & 2 & 115.111 & 92.91 & .00 \\
Age*impulsivity & 6811.764 & 107 & 6.325 & 7 & 0 \\
Error & 24290.000 & 7 & & & \\
\hline
\end{tabular}




\begin{tabular}{lllll}
\hline Total & 7041.985 & 108 & 18.20 & .00 \\
Corrected Total & 0 & 0 & 0 \\
& & 107 & & \\
& 9 & & \\
\hline
\end{tabular}

R Squared $=.004$ (Adjusted R Squared $=.031$ )

The result of the analysis of covariance (on table 3 ) indicated that there is a significant effect of the covariate (family type) on the influence of impulsivity on sexual behaviour of undergraduates in Southwestern Nigeria. A preliminary analysis evaluating the homogeneityof-regression assumption indicated that the covariate (family type) intervenes significantly on the influence of impulsivity on the sexual behaviour of undergraduates in Southwestern Nigeria, $\mathrm{F}(2,1077)=25.41, \mathrm{p}<0.05$. Hence, family type intervenes significantly the influence of impulsivity on the sexual behaviour of undergraduates. The Levene's test was not significant ( $p$ $<.05)$ which means we have not violated our assumption of homogeneity of variances. Therefore, the result of the analysis is accepted, and the hypothesis also is accepted.

Table 3. Summary of ANCOVA of impulsivity on sexual behaviour by family type

\begin{tabular}{lllllc}
\hline Source & $\begin{array}{l}\text { Type III Sum } \\
\text { of } \\
\text { Squares }\end{array}$ & Df & $\begin{array}{l}\text { Mean } \\
\text { Square }\end{array}$ & F & Sig. \\
\hline Corrected Model & 317.257 & 2 & 158.629 & 25.405 & .00 \\
Intercept & 2046.797 & 1 & 2046.797 & 327.80 & 0 \\
Familytype*impulsivity & 317.257 & 2 & 158.629 & 5 & .00 \\
Error & 6724.728 & 107 & 6.244 & 25.405 & 0 \\
Total & 24290.000 & 7 & & & .00 \\
Corrected Total & 7041.985 & 108 & & 0 \\
& & 0 & & \\
& & 107 & & & \\
\hline
\end{tabular}

R Squared $=.004$ (Adjusted R Squared $=.043$ )

As shown in table 4, a one-way analysis of covariance (ANCOVA) was conducted for this hypothesis. The independent variable was impulsivity; the dependent variable was sexual behaviour while the intervening variables controlled for were age, family type and peer pressure, which is the covariate. The analysis evaluating the homogeneity-of-regression assumption indicated that the covariate (peer pressure) intervenes significantly on the influence of impulsivity on the sexual behaviour of undergraduates in Southwestern Nigeria, F $(2,1077)$ $=53.13, \mathrm{p}<0.05$

Table 4. Summary of ANCOVA of impulsivity on sexual behaviour by peer pressure

\begin{tabular}{lllllc}
\hline Source & $\begin{array}{l}\text { Type III Sum of } \\
\text { Squares }\end{array}$ & Df & $\begin{array}{l}\text { Mean } \\
\text { Square }\end{array}$ & F & Sig. \\
\hline Corrected Model & 632.406 & 2 & 316.203 & 53.13 & .00 \\
Intercept & 327.410 & 1 & 327.410 & 1 & 0 \\
Peerpressure*impulsivity & 632.406 & 2 & 316.203 & 55.01 & .00 \\
Error & 6409.579 & 107 & 5.951 & 5 & 0 \\
Total & 24290.000 & 7 & & & \\
\hline
\end{tabular}




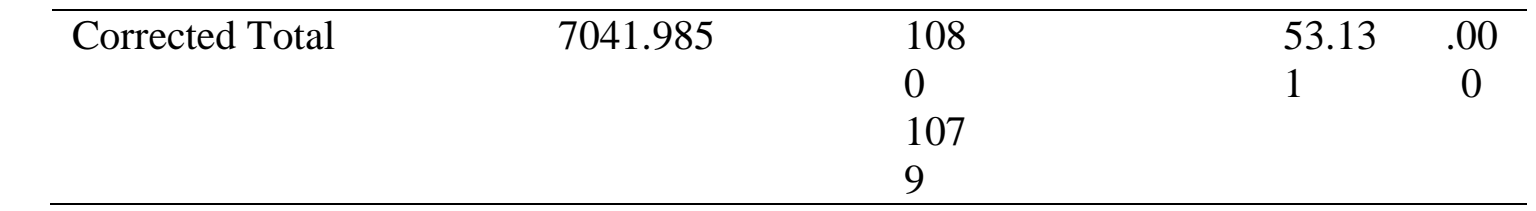

$\mathrm{R}$ Squared $=.004$ (Adjusted R Squared $=.088$ )

\section{Discussion}

The study found that impulsivity had a significant influence on the sexual behaviour of undergraduates. That is, undergraduates who have low impulse are more likely to be participating in sexual behaviour than undergraduates with high impulse. This finding contradicts most study reviewed in this study. According to Charnigo et al. (2013) impulsive decision-making was oftentimes connected with sexual risk behaviours over the 11 risk-related outcomes.

Hoyle, et al. (2000) suggested that among substantive findings, impulsivity had effects on all sexual risk-taking behaviour in their study, this may be due to the inconsequential thinking of most adolescents, as many adolescents at this age are interested in exploring their world especially sexually which according to Sigmund Freud's Psychosexual Theory (Genital Stage) sexual impulses reemerge at this stage. Adolescents and young adults therefore may have to struggle through for a while before they learn some balancing. Also, low level of sexual education given by parents, caregivers, and the society at large to adolescents may contribute to their uninformed and impulsive decision making.

Clift et al. (1993) in their study affirmed that in sexual behaviour, "non-users of condom were expected to be more venturesome and impulsive, particularly in the context of casual relationships". This position can be expected because the inability to control or manage sexual urge may sometimes make some individuals forget protection or even damn any potential consequence just to gratify that instant desire, when this is the case, then one can psychoanalytically conclude they had anal fixation or their id took a better part of them. Physiologically, sensation seeking, or impulsivity's relationship is traceable to the heightened distribution of dopamine to the ventral striatum (Chambers, Taylor \& Potenza, 2003).

Many studies have affirmed the adventurous attitude of children, adolescents and young adults. Adolescents tend to be more curious about their world, they are interested in test-running anything that gets their attention, and this can explain the reason for both early sexual initiation, little or no interest in the use of condoms, and some other risky sexual related behaviours among adolescents. Khurana et al. (2012) reported that impulsivity is positively similar with early sexual initiation which supports the findings of this study, and this explains the need for early and later intervention with parents and family and peers respectively.

Charnigo et al. (2013) reported that sensation seeking and impulsive decision-making worked interactively with regard to the outcome variables of sexual acts using drugs, sexual acts with a partner using alcohol, and sexual acts with a partner using drugs. Romer and Hennessy (2007) found that the influence of sensation seeking is moderated by the same process that is essential to adult decision making, which are, the use of emotions as the basis for evaluating behavioural alternatives. They also found that sensation seeking explain reasons for an increase in risky behaviour during adolescence. The study of McCoul and Haslam (2001) also supports that impulsivity and sensation seeking were correlated with frequency of unprotected sex among heterosexual partners. Impulsive behavior can be just what it is "impulse" and the id overdevelopment as against the ego appeal, which undertones sensation seeking, can be associated with unprotected sex. That is, before protection is considered the act would have been done impulsively just to gratify that sexual pleasure as soon as possible. 
The finding also showed that age (adolescents and young adults), family type (single parenthood, monogamous and polygamous), and peer pressure (low and high) each had an intervening effect on the influence of impulsivity on the sexual behaviour of undergraduates. That is, undergraduates who act on impulse had significantly more tendency of engaging in sexual behaviour, controlling for age, family type and peer pressure which correlates the findings of Khurana, et al. (2012) reporting that "the effects of 3 prominent risk factors (Black racial identity, low socioeconomic background, and early pubertal maturation) on early sexual initiation were entirely mediated by working memory and impulsivity". The report of Dir, Coskunpinar, Cyders (2014) also that highlighted gender, age, race, and study design as having significant though small effects on risky sexual behavior among adolescents while Jardin, Sharp, Garey, \& Zvolensky (2017) suggested that risky sex may serve to control how an individual typically experience aversion emotions.

\section{Conclusion}

\section{Strength and Limitations}

There were some limitations noted in this study. Firstly, the study was a descriptive cross-sectional study which means that causation could not be established but only associations and relationships. Secondly, the respondents of the study were limited to undergraduates which means the findings may not be generalizable to the population. However, future research is needed to further establish the association between impulsivity and risky sexual behaviour among undergraduates across the six geo-political zones of Nigeria. These limitations notwithstanding, the study provides further insights into risky sexual behaviour of adolescents and young adults.

\section{REFERENCES}

Aboki, H., Folayan, M. O., Daniel, U., \& Ogunlayi, M. (2014). Changes in HIV sexual risk behaviour among adolescents aged 15-19 years over a five-year period - Is the HIV prevention programme in Nigeria yielding results? African Journal of Reproductive Health, 18, 108-116.

Adebayo, F. (1996, February 18). Most Nasty Movements. Sunday Tribune. P.12.

Adedipe, V. O. (2000, October 14). The adolescent problem behaviour (ii). Saturday Tribune.

Agiobu-Kemmer, I. S. (2009). A model of the total human lifespan. In Agiobu-Kemmer (Ed): Growing up: Theories and Stories. Lagos: Springfield Books

Bhattacharya, P. (2016). A comparative study between two gender groups of home environment: effect of their emotional intelligence of middle-income group school students. International Journal of Development Research, 6(4), 7562-7564.

Carrier, E. F., Nolet, K., Cyr, G., Rouleau, J. L., \& Gagnon, J. (2016). Sexual impulsivity and problematic sexual behaviors in adults: Towards innovative domain-specific behavioral measures. Sexologies, 25(4), e77e82. doi: https://doi.org/10.1016/j.sexol.2015.12.002

Chambers, R. A., Taylor, J. R., \& Potenza, M. N. (2003). Developmental neurocircuitry of motivation in adolescence: A critical period of addiction vulnerability. American Journal of Psychiatry, 160, 10411052.

Charnigo, R., Noar, S. M., Garnett, C., Crosby, R., Palmgreen, P., \& Zimmerman, R. S. (2013). Sensation Seeking and Impulsivity: Combined Associations with Risky Sexual Behavior in a Large Sample of Young Adults. The Journal of Sex Research, 50(5), 480-488. doi:10.1080/00224499.2011.652264

Clift, S. M., Wilkins, J. C., \& Davidson, E. A. F. (1993). Impulsiveness, venturesomeness and sexual risk-taking among heterosexual GUM clinic attenders. Personality and Individual Differences. 15(4), 403-410.

Cyders, M. A., \& Smith, G. T. (2008). Emotion-based dispositions to rash action: Positive and negative urgency. Psychological Bulletin. 134(6), 807-828.

Daruna, J. H. \& Barnes, P. A. (1993). A neurodevelopmental view of impulsivity. In W. G. McCown, J. L. Johnson, 
M. B. Shure (Eds). The impulsive client: Theory, research and treatment. Washington, DC: APA

Dickman, S. J. (1990). Functional and dysfunctional impulsivity: Personality and cognitive correlates. Journal of Personality and Social Psychology, 58, 95-102.

Dir, A. L., Coskunpinar, A., \& Cyders, M. A. (2014). A meta-analytic review of the relationship between adolescent risky sexual behavior and impulsivity across gender, age, and race. Clinical Psychology Review, 34(7), 551-562. doi: https://doi.org/10.1016/j.cpr.2014.08.004

Dougherty, D. M., Bjork, J. M., Huckabee, H. C., Moeller, F. G., \& Swann, A. C. (1999). Laboratory measures of aggression and impulsivity in women with borderline personality disorder. Psychiatry Research 85, 315326.

Durowade, K. A., Babatunde, O. A., Omokanye, L. O., Elegbede, O. E., Ayodele, L. M., Adewoye, K. R., et al. (2017). Early sexual debut: prevalence and risk factors among secondary school students in Ido-ekiti, Ekiti state, South-West Nigeria. African Health Sciences, 17, 614-622. 10.4314/ahs.v17i3.3

Evenden, J. L. (1999). Varieties of impulsivity. Psychopharmacology, 146, 348-361.

Envuladu, E. A., de Kwaak, A. V., Zwanikken, P., \& Zoakah, A. I. (2017). Exploring the factors influencing adolescent sexual behavior in plateau state Nigeria. American Journal of Medicine and Medical Sciences, 7, 1-6. 10.5923/j.ajmms.20170701.01

Eysenck, S. B. and Eysenck, H. J. (1977). The place of impulsiveness in a dimensional system of personality description. British Journal Social Clinical Psychology, 16, 57-68.

Fatusi, A. O. \& Blum, R. W. (2008). Predictors of early sexual initiation among a nationally representative sample of Nigerian adolescents. BMC Public Health, 8 DOI: 10.1186/1471-2458-8-136

Federal Ministry of Health. National HIV \& AIDS and Reproductive Health Survey, 2004 (NARHS Plus) Federal Ministry of Health; Abuja, Nigeria: 2005.

Federal Ministry of Health. National HIV \& AIDS and Reproductive Health Survey, 2012 (NARHS Plus) Federal Ministry of Health; Abuja, Nigeria: 2013.

Federal Office of Statistics (FOS) and IRD/Macro International, Inc. (IRD) 2008: Nigeria Demographic and Health Survey 2008. Columbia, Maryland: IRD/Macro

Federal Office of Statistics (FOS) and IRD/Macro International, Inc. (IRD) 2013: Nigeria Demographic and Health Survey 2013. Columbia, Maryland: IRD/Macro

Folayan, M. O., Adebajo, S., Adeyemi, A., \& Ogungbemi, K. M. (2015). Differences in Sexual Practices, Sexual Behavior and HIV Risk Profile between Adolescents and Young Persons in Rural and Urban Nigeria. PLoS ONE 10(7): e0129106. doi:10.1371/journal.pone.0129106

Folayan, M. O., Odetoyinbo, M., Brown, B., \& Harrison, A. (2014). Differences in sexual behaviour and sexual practices of adolescents in Nigeria based on sex and self-reported HIV status. Reproductive Health, 11, 83. $10.1186 / 1742-4755-11-83$

Freedman. R. (2000). Do family Planning Programme affect fertility reference? A Literature Review. Studies in Family Planning, 28, 1-13.

Hall, P. A., Holmqvist, M., \& Sherry, S. B. (2004). Risky Adolescent Sexual Behavior: A Psychological Perspective for Primary Care Clinicians. Topics in Advanced Practice Nursing eJournal. 4(1)

Horvath, P. \& Zuckerman, M. (1993). Sensation seeking, risk appraisal, and risky behaviour. Personality and Individual Differences, 14 (1), 41-52 http://dx.doi.org/10.1016/0191-8869(93)90173-Z

Hoyle, R. H., Fejfar, M. C. \& Miller, J. D. (2000). Personality and Sexual Risk Taking: A Quantitative Review. Journal of Personality, 68(6), 1203-1231.

Imaledo, J. A., Peter-kio, O. B, \& Asuquo, E. O. (2012). Pattern of risky sexual behaviour and associated factors among undergraduate students of the University of Port Harcourt, Rivers State, Nigeria. The Pan African Medical Journal, 12, 97, DOI:10.11604/pamj.2012.12.97.1384

Jardin, C., Sharp, C., Garey, L., \& Zvolensky, M. J. (2017). The Role of Impulsivity in the Relation Between Negative Affect and Risky Sexual Behaviors. Journal of Sex \& Marital Therapy, 43(3), 250-263. doi:10.1080/0092623X.2016.1141821

John, C., Okolo, S. N., \& Isichei, C. (2014). Sexual risk behavioour and HIV infection among adolescents in secondary schools in Jos, Nigeria. Nigerian Journal of Paediatrics, 41(2): http://dx.doi.org/10.4314/njp.v41i2.1

Khurana, A., Romer, D., Betancourt, L. M., Brodsky, N. L., Giannetta, J. M., \& Hurt, H. (2012). Early adolescent sexual debut: The mediating role of working memory ability, sensation seeking, and impulsivity. Developmental Psychology, 48(5), 1416-1428. doi:10.1037/a0027491

Madden G. J. \& Johnson, P. S. (2010). A delay discounting primer. In G. J. Madden and W. K. Bickel (Eds). Impulsivity: The behavioural and neurological science of discounting, 11-37. Washington, DC: APA.

Marinkovic, K., Halgren, E., Klopp, J., \& Maltzman, I. (2000). Alcohol effects on movement-related potentials: a measure of impulsivity? Journal of Studies on Alcohol, 61, 24-31.

McCoul, M. D. \& Haslam, N. (2001). Predicting high risk sexual behaviour in heterosexual and homosexual men: 
the roles of impulsivity and sensation seeking. Personality and Individual Differences 31(8), 1303-1310. http://dx.doi.org/10.1016/S0191-8869(00)00222-1

National Population Commission: National Demographic Health Survey in Nigeria, 2004, 3:26-29.

Ndu, A. (2000). The role of the family in managing indiscipline among youths in Nigeria. Journal of Counselling. $1(1), 45-51$.

Nnachi, R. O. (2003). Causes, consequences and control of behaviour problems among Nigerian children in Nnachi, R. O. and Ezeh, P. S. E. (Eds.). (2003). The behaviour problems of the Nigerian Child. Awka: The Nigerian Society for Educational Psychologists (NISEP).

Nnebue, C. C., Chimah, U. C., Duru, C. B., Illika, A. L., \& Lawoyin, T. O. (2016). Determinants of age at sexual initiation among Nigerian adolescents: A study of secondary school students in a military barracks in Nigeria. American Journal of Medical Sciences and Medicine, 4(1), 1-7.

Odoemelam, A. (1996). Incidence and management of male and female sexually maladjusted youngsters: gender and counselling implications. The Counsellor: Journal of the Counselling Association of Nigeria. 14 (92), $160-171$.

Oyedeji, O. O. (2006). Dating and Sexual Behaviour among Undergraduate of Obafemi Awolowo University, IleIfe. (Unpublished).

Patton, J. H., Stanford, M. S., \& Barratt, E. S. (1995). Factor structure of the Barratt Impulsiveness Scale. Journal of Clinical Psychology, 51, 768-774.

Rachlin, H. (2000). The science of self-control. Cambridge, MA: Harvard.

Ritchwood, T. D., Ford, H., DeCoster, J., Sutton, M. \& Lochman, J. E. (2015). Risky sexual behavior and substance abuse among adolescents: A meta-analysis. Children and Youth Services Review, 52, Pp 74-88.

Romer, D. (2010) Adolescent Risk taking, Impulsivity, and Brain Development: Implications for Prevention. Wiley Periodicals, Inc. Developmental Psychobiology 52: 263-276, 2010. DOI 10.1002/dev.20442

Romer, D., \& Hennessy, M. (2007). A biosocial-affect model of adolescent sensation seeking: The role of affect evaluation and peer-group influence in adolescent drug use. Prevention Science, 8, 89-101.

Silverman, E. A. (2013). Adolescent sexual risk-taking in a psychosocial context: Implication for HIV prevention. HIV Clinician, 25(2), 1-5.

Stein, D. J., Hollander, E., Simeon, D., \& Cohen, L. (1994). Impulsivity scores in patients with obsessivecompulsive disorder. Journal of Nervous and Mental Disorder, 182, 240-241.

Stein, D. J., Trestman, R. L., Mitropoulou, V., Coccaro, E. F., Hollander, E., and Siever, L. J. (1996). Impulsivity and serotonergic function in compulsive personality disorder. Journal of Neuropsychiatry Clinical Neuroscience, 8, 393-398.

Steinberg, L (2002). Adolescence (6th ed.). New York: McGraw-Hill.

Steinberg L, \& Morris A.S. (2001). Adolescent development. Annual Review of Psychology, 52, 83-110

Van der Linden, M., d' Acremont, M., Zermatten, A., Jermann, F., Larøi, F. \& Willems, S. (2006). A French adaptation of the UPPS Impulsive Behaviour scale: confirmatory factor analysis in a sample of undergraduates. European Journal of Psychological Assessment 22, 38-42.

VandenBos, G. R. (2007). APA Dictionary of Psychology. Washington, DC: APA

Wellings, K. (2006). Sexual behaviour in context: A global perspective. Lancet, 368 (9548), 1706-1728. http://dx.doi.org/10.1016/S0140-6736(06)69479-8

Whiteside, S. P. \& Lynam, D. R. (2001). The five-factor model and impulsivity: using a structural model of personality to understand impulsivity. Personality Individual Differerences, 30(4), 669-689.

WHO (2002). World Health Organization. Estimation of the incidence and prevalence of sexually transmitted infections. WHO, Geneva (2002)

Winters, K. C., Botzet, A. M., Fahnhorst, T., Baumel, L., \& Lee, S. (2008). Impulsivity and Its Relationship to Risky Sexual Behaviors and Drug Abuse. Journal of Child \& Adolescent Substance Abuse, 18(1), 43-56. doi:10.1080/15470650802541095. 